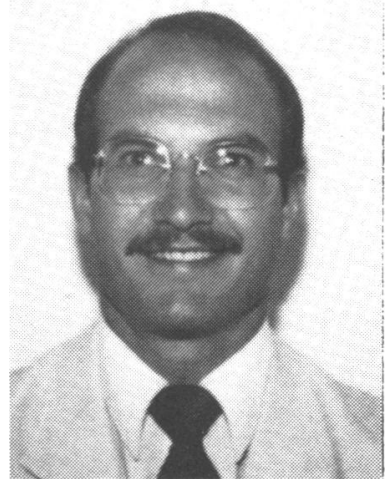

D. W. Bacharach

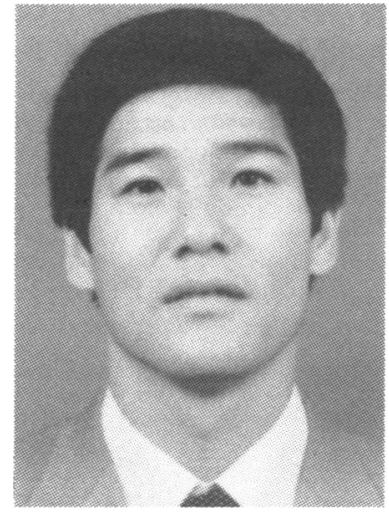

T. Moritani

\title{
STRIDE FREQUENCY AND VENTILATION AT CONSTANT CARBON DIOXIDE OUTPUT
}

\author{
M. J. BERRY, PhDt, D. W. BACHARACH, MS and T. MORITANI, PhD*
}

Human Performance Laboratory, Department of Physical Education, Texas A \& M University, College Station, TX 77843

\section{ABSTRACT}

To determine the consequences of two different stride frequencies on ventilation (VE) at similar levels of carbon dioxide production $\left(\mathrm{VCO}_{2}\right)$, eleven male subjects performed two work tests on the treadmill. One test involved walking at a speed of $5 \mathrm{~km} / \mathrm{hr}$ on a $15 \%$ grade while the other consisted of running on the treadmill at $9 \mathrm{~km} / \mathrm{hr}$ on a $0 \%$ grade. Running increased stride frequency by $47 \%$. The running and walking tests resulted in similar $\mathrm{VCO}_{2}$ levels, $1.85 \pm .18$ and $1.9 \pm .20 \mathrm{l} / \mathrm{min} \mathrm{respec}-$ tively, a non-significant difference. Ventilation during running was $43.73 \pm 6.51 \mathrm{l} / \mathrm{min}$ and during walking was $43.26 \pm 6.79$ $\mathrm{l} / \mathrm{min}$, a non-significant difference. In addition the time constants for oxygen consumption $\left(\mathrm{VCO}_{2}\right), \mathrm{VE}$ and $V \mathrm{CO}_{2}$ were measured. The time constants for $\mathrm{VCO}_{2}$ and $\mathrm{VE}$ were not found to differ significantly during either the running or walking test. From our results, it can be seen that VE is more closely aligned to the metabolic state rather than stride frequency. In addition, the coupling of $\mathrm{VE}$ and $\mathrm{VCO}_{2}$ during the non-steady state is further indicative that ventilation is linked to the metabolic demands of the body.

Index terms: $\mathrm{VCO}_{2}$, Ventilatory control, Hypernea, Stride frequency

\section{INTRODUCTION}

Control of the pulmonary system during exercise is attributed to either a humourally or neurally mediated control system. After almost a century of debate, there is still no clear concensus as to which mechanism is responsible for exercise hypernoea. Filley and Heineken (1976), Wasserman et al (1974) and Yamamoto (1962) have all suggested mechanisms for a humourally mediated control of ventilation. Kao et al (1955, 1963), with their cross circulation studies suggested afferent feedback from the working muscle as a control mechanism, while Eldridge (1977) has advocated the contribution of central neural control.

(1980) and McMurray and Ahlborn (1982) have all shown a relationship between movement frequency and respiratory frequency and have suggested a neurogenic input to ventilatory control. While McMurray and Ahlborn (1982) held oxygen consumption $\left(\mathrm{VO}_{2}\right)$ at a constant value for varying stride frequencies, neither of the other two investigations examined the metabolic rates during exercise. The relationship of $\mathrm{VCO}_{2}$ and $\mathrm{VE}$ to stride frequency was not examined in the studies by Bechbache and Duffin (1977), Jasinskas et al (1980) nor McMurray and Ahlborn (1982).

\section{tCorrespondence to:}

Dr. Michael Berry

Exercise Physiology Laboratory Department of Physical Education The University of North Carolina Chapel Hill, NC 27514, USA
*Present address:

Dr. T. Moritani

Human Performance Laboratory Hoken-taiku

Kyoto University

Japan
Sakyo-ku, Kyoto 606
It was therefore the purpose of this investigation to examine the effects of stride frequency on ventilation when $\mathrm{VCO}_{2}$ was held constant. In addition, the relationship among the kinetic responses of $\mathrm{VE}, \mathrm{VCO}_{2}$ and $\mathrm{VO}_{2}$ during the non steady state of exercise were also examined.

\section{METHODS}

Eleven volunteer male subjects participated in this study and a summary of the mean descriptive data for all subjects are presented in Table I. Subjects signed informed consent after being told of the experimental procedures, but were unaware of the purpose of the investigation. Two visits to the laboratory were required of each subject. I During the first visit, the subject performed an incremental exercise test on a Quinton treadmill using a protocol similar to the one used by Davis et al (1976) for the determination of maximal oxygen consumption ( $\mathrm{VO}_{2} \mathrm{max}$ ) and the anaerobic threshold (AT). The AT was determined using the criteria of an increase in the ventilatory equivalent of oxygen $\left(\mathrm{VEN} / \mathrm{NO}_{2}\right)$ and fraction of expired oxygen $\left(\mathrm{FEO}_{2}\right)$ while the ventilatory equivalent of carbon dioxide (VEN $N \mathrm{CO}_{2}$ ) remains constant as suggested by Caiozzo et al (1982). During the second visit, the subject performed two work tests below the AT on the treadmill. One test involved walking on the treadmill at a speed of $5 \mathrm{~km} / \mathrm{hr}$ at a $15 \%$ grade. The other test consisted of running at a speed of $9 \mathrm{~km} / \mathrm{hr}$ at a $0 \%$ grade. Speed and grade of each test were determined in a pilot study using four of the subjects and were designed to elicit a similar $\mathrm{VCO}_{2}$ in each of the subjects. Subjects were assigned randomly for the order in which the tests were to be performed. The protocol for each of the two tests consisted of the subject standing on the treadmill for a period of two minutes, then instructed to start the exercise test. The exercise period lasted six minutes after which the subject was seated. During all stages of the test and at rest the variables of heart rate (HR), $\mathrm{VO}_{2}, \mathrm{VCO}_{2}$ and $\mathrm{VE}$ were monitored (see below). Once these variables had returned to their pre-exercise values, the subjects completed the remaining test. If any of these variables failed to return to a resting level within $\mathbf{3 0}$ minutes of completion of the first test, the subject was asked to return on the following day to complete the remaining test.

During all three tests, the subjects breathed through a low resistance breathing valve (Rudolph \#2700). Expired gases passed through a Hewlett 
TABLE I

Mean physical and some physiological characteristics of subjects.

\begin{tabular}{ccccccc}
\hline & $\begin{array}{c}\text { Age } \\
(\mathrm{yrs})\end{array}$ & $\begin{array}{c}\text { Height } \\
(\mathrm{cm})\end{array}$ & $\begin{array}{c}\text { Weight } \\
(\mathrm{kg})\end{array}$ & $\begin{array}{c}\mathrm{VO}_{2} \max \\
(1 / \mathrm{min})\end{array}$ & $\begin{array}{c}\mathrm{AT}^{*} \\
(1 / \mathrm{min})\end{array}$ & $\begin{array}{c}\mathrm{AT}^{*} \\
\left(\% \mathrm{VO}_{2}\right)\end{array}$ \\
\hline $\begin{array}{c}\text { Mean } \\
\text { SD }\end{array}$ & 30.8 & 163.6 & 3.82 & 2.44 & 63.9 & \\
\hline
\end{tabular}

*denotes 'anaerobic threshold'

Packard (\# 21073B) pneumotachograph which, was connected to a Hewlett Packard (\# 47304A) respiratory flow transducer, and into a 5 litre mixing chamber. Tidal volume (VT) was obtained by integrating expired air flow with a Hewlett Packard (HP9825A) computer and was used for the determination of VE by multiplying it by the breathing frequency. Expired $\mathrm{CO}_{2}$ was determined with a Beckman LB-2 analyser, and expired $\mathrm{O}_{2}$ with an Applied Electrochemistry S-3 analyser. Both analysers were calibrated routinely throughout the tests using precision analysed gas mixtures. Expired gas was sampled from the mixing chamber to each of the analysers at a rate of $500 \mathrm{ml} / \mathrm{min}$. The electrical outputs from the gas analysers and the flow transducers were connected, via analog to digital coversion, then to a Hewlett Packard (HP9825A) computer which was programmed to calculate and display minute values every 15 sec throughout the two minutes prior to the start of exercise and the exercise periods. Heart rate was monitored in all subjects using a CM5 lead configuration with a Dynopack Life System.

To determine the time constants for $\mathrm{VO}_{2}, \mathrm{VCO}_{2}$, and VE the data were analysed using a Hewlett Packard (HP 9836) computer. Resting values were derived by averaging $15 \mathrm{sec}$ sampling periods over a two minute period prior to the start of exercise. Steady state was calculated as the average of the 15 sec sampling periods during the 5th and 6 th minutes of exercise. The time course of the transition from rest to steady state was calculated from the average $15 \mathrm{sec}$ values. Time constants, the time for an exponential process to achieve approximately $63.2 \%$ of the steady state value, were determined graphically by plotting the time courses of the difference between steady state and transitional values on a semilogarithmic plot (see Fig. 1).

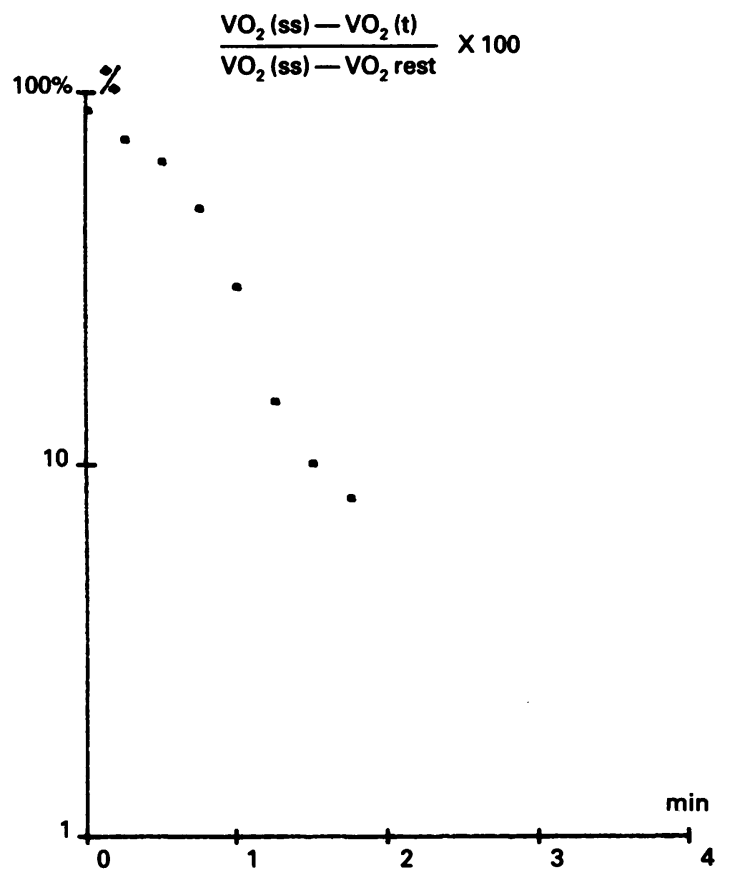

Fig. 1: Graphical representation of the oxygen kinetics curve on logarithmic scale. All time constants were found by solving the above equation where VE and $\mathrm{VCO}_{2}$ were substituted for $\mathrm{VO}_{2}$.

The variables of stride frequency (SF), $\mathrm{HR}, \mathrm{VO}_{2}, \nabla \mathrm{CO}_{2}$ and $\nabla E$ from the steady states of both tests were analysed using a correlated t-test. The time constants of $\mathrm{VE}, \mathrm{VCO}_{2}$ and $\mathrm{VO}_{2}$ were analysed using ANOVA. If the omnibus "F" was found to be significant, Duncan's test was used in order to determine the exact nature of the difference.

\section{RESULTS}

Resting values, prior to the start of each exercise test, for $\mathrm{VO}_{2}, \mathrm{HR}, \mathrm{VCO}_{2}, \mathrm{VE}$ and $R$ are shown in Table II. It an be seen from this table that all the metabolic variables we monitored returned to their resting levels prior to the start of the
TABLE \|

Comparison of mean resting metabolic values prior to Test 1 and Test 2

\begin{tabular}{cccccc}
\hline & $\mathrm{VO}_{2}$ & $\mathrm{VCO}_{2}$ & $\mathrm{VE}$ & Heart Rate & $R$ \\
& $(1 / \mathrm{min})$ & $(1 / \mathrm{min})$ & $(1 / \mathrm{min})$ & $($ beats $/ \mathrm{min})$ & \\
\hline Test 1 & $0.27 \pm 0.09$ & $0.23 \pm 0.06$ & $8.27 \pm 2.15$ & $66 \pm 9$ & $0.87 \pm 0.09$ \\
Test 2 & $0.28 \pm 0.05$ & $0.25 \pm 0.05$ & $8.74 \pm 2.12$ & $67 \pm 9$ & $0.90 \pm 0.08$ \\
\hline
\end{tabular}

None of these variables were found to differ significantly.

second test. Only one subject was required to return to the laboratory on the following day in order to complete his testing, being unable to complete during one session as his metabolic variables failed to return to a resting level within the alloted time period.

Values for $\mathrm{VO}_{2}, V \mathrm{VO}_{2}, \mathrm{R}, \mathrm{VE}, \mathrm{HR}$ and stride frequency (SF) during the walking test and during the running test are shown in Table III. Running resulted in a $47 \%$ increase in stride frequency when compared with walking $(P<0.001)$. Stride frequency increased from $108 \pm 9$ strides $/ \mathrm{min}$ to $159 \pm 8$ strides/min during running. The mean $\mathrm{VCO}_{2}$ during running was $1.85 \pm 0.18$ $\mathrm{l} / \mathrm{min}$ and during walking was $1.95 \pm 0.20 \mathrm{l} / \mathrm{min}$. This $100 \mathrm{ml} / \mathrm{min}$ was minimal and not found to be significant. The walking test required an average $\mathrm{VO}_{2}$ of $2.10 \pm 0.31 \mathrm{ml} / \mathrm{min}$ while the running test required an average $\mathrm{VO}_{2}$ of $2.08 \pm$ $0.24 \mathrm{l} / \mathrm{min}$, a non-significant difference. $R$ values for steady state during running and walking were $0.88 \pm 0.07$ and $0.90 \pm 0.05$ respectively, also a non-significant difference. Mean heart rates during steady state running and walking were both 130 beats/min. While we were only concerned with holding $\mathrm{VCO}_{2}$ constant during the two tests, this resulted in a similarity between other metabolic markers. The running test yielded an average VE of $43.73 \pm 6.51 \mathrm{l} / \mathrm{min}$ and this was not found to be significantly different from the walking value of $43.26 \pm 6.71 \mathrm{l} / \mathrm{min}$, despite the $47 \%$ increase in stride frequency.

TABLE III

Comparison of mean physiological and mechanical variables during steady state running and walking (values are mean \pm SD)

\begin{tabular}{lcccccc}
\hline & $\begin{array}{c}\mathrm{VO}_{2} \\
(1 / \mathrm{min})\end{array}$ & $\begin{array}{c}\mathrm{VCO}_{2} \\
(1 / \mathrm{min})\end{array}$ & $\begin{array}{c}\mathrm{VE} \\
(1 / \mathrm{min})\end{array}$ & $\begin{array}{c}\mathrm{HR} \\
(\mathrm{b} / \mathrm{min})\end{array}$ & $\begin{array}{c}\text { SF* } \\
(\mathrm{s} / \mathrm{min})\end{array}$ & $R$ \\
\hline Walk & $2.10 \pm 0.31$ & $1.95 \pm 0.20$ & $43.26 \pm 6.79$ & $130 \pm 10$ & $108 \pm 9$ & $0.90 \pm 0.05$ \\
Run & $2.08 \pm 0.24$ & $1.85 \pm 0.18$ & $43.73 \pm 6.51$ & $130 \pm 10$ & $159 \pm 8$ & $0.88 \pm 0.07$
\end{tabular}

*Significant difference $(P<0.001)$ between stride frequencies.

During the transition from rest to steady state, kinetic analysis was done to determine the time constants for $\mathrm{VE}, \mathrm{VCO}_{2}$ and $\mathrm{VO}_{2}$. Plots of the three variables during running and walking are illustrated in Figs. 2 and 3 . No significant differences between the time constants of $\mathrm{VE}$ and $\mathrm{VCO}_{2}$ were found during running or walking. In both instances, VE was found to lag slightly behind $\mathrm{VCO}_{2}$. The time constants for $\mathrm{\nabla O}_{2}$ were found to be significantly faster than both $\mathrm{VE}$ and $\mathrm{VCO}_{2}$ during both running and walking.

\section{DISCUSSION}

From our results, it is apparent that the change in stride frequency produced no appreciable change in ventilation when the production of carbon dioxide was held constant. These findings appear to be in conflict with those of McMurray and Ahlborn (1982), who found that when the metabolic rate was held constant an increase in ventilation would be concommitant with an increase in stride frequency. One reason for this discrepancy may be due in part to methodology. The running speed and prcent grade used in our study were determined in order to provide for a similar $\mathrm{VCO}_{2}$, but the protocols used by McMurray and Ahlborn (1982) were determined to provide for analogous metabolic rates with $\mathrm{VO}_{2}$ and heart rate serving as the metabolic markers. While we inadvertently held $\mathrm{VO}_{2}$ and heart rate constant during both testing procedures, we chose $\mathrm{VCO}_{2}$ to serve as the metabolic marker. Another possibility for the disparity between the two investigations is that the protocols used during walking were different. Our subjects walked at $5.0 \mathrm{~km} / \mathrm{h}$ at a $15 \%$ grade while the subjects in the study of McMurray and Ahlborn (1982) walked at $5.8 \mathrm{~km} / \mathrm{h}$ at an $8 \%$ grade. A final reason suggested for the conflicting results is the subjects' level of fitness and training. The mean $\mathrm{VO}_{2}$ max in our subjects was $46.52 \mathrm{ml} / \mathrm{kg} / \mathrm{min}$. 
McMurray (personal communication) reported the $\mathrm{VO}_{2}$ max of their subjects to be close to $60.0 \mathrm{ml} / \mathrm{kg} / \mathrm{min}$, indicating highly fit and trained individuals. Hanson et al (1982) found that running on a $0-3 \%$ grade elicited a $10-25 \%$ increase in breathing frequency and VE when compared to walking on a $14-24 \%$ grade. All subjects employed in Hanson et al (1983) investigation were also highly trained exhibiting $\mathbf{V O}_{2}$ max values in excess of $58.0 \mathrm{ml} / \mathrm{kg} / \mathrm{min}$. In fact, all of these subjects had competed for at least 5 years in competitive middle and long distance races. Bramble and Carrier (1983) studied locomotor-respiratory coupling (LRC) in experienced runners and persons with little or no running experience. These authors found breathing and gait to be coupled tightly in the experienced runners while those with a paucity of running experience demonstrated little or no tendency to synchronise gait and respiration. Even individuals in good physical condition who maintained a fitness programme other than running showed no signs of entrainment. Whether entrainment is a learned response as a result of extensive training is a question that must be answered with future research. The work of Bramble and Carrier (1983), Hanson et al (1982) and McMurray and Ahlborn (1982) all suggest a link between VE and stride frequency in trained individuals. The fact that we did not find this link may be in part due to us using only moderately fit individuals. Based on these other studies, it does not seem unreasonable that stimulation of neurogenic origin from higher braion centres (Eldridge et al, 1981) may provide a feedfoward drive for ventilation.

Our finding a link between $\mathrm{VCO}_{2}$ and $\mathrm{VE}$ is corroborative of other investigations using both treadmill and bicycle ergometry protocols. Kay et al (1975) found the relationship between VE and $\mathrm{VCO}_{2}$ to be irrespective of pedal frequency during steady state exercise. These investigators reported VE to be a linear function of $\mathrm{VCO}_{2}$. A study by Dixon et al (1961) showed there to be no relationship between respiratory rate and the frequency of limb movement. Casaburi and associates (1977) had their subjects work on a cycle ergometer against a constant work load with varying pedal frequencies and noted that changes in VE were closely aligned and ascribable to changes in $\mathrm{VCO}_{2}$. The variation in pedal frequency was not found to produce a change in VE independent of $\mathrm{VCO}_{2}$. Dejours (1967) stated there may be little difference in VE when the work load is held constant during two different combinations of treadmill speed and grade. While we did not plan to hold $\mathrm{VO}_{2}$ constant a priori, analysis of our data did show the metabolic cost of the two protocols to be equated. Thus our findings are in agreement with Dejours.

In addition to studying the relationship of $\mathrm{VE}$ and $\mathrm{VCO}_{2}$ during the steady state phase of exercise, we also examined the kinetic responses of these two variables, along with $\mathrm{VO}_{2}$, during the transition from rest to steady state. While our methods for kinetic analysis were susceptible to extraneous contamination due to our analytical procedures, the coupling between $\mathrm{VE}$ and $\mathrm{VCO}_{2}$ is easily noted. We found no significant difference between the time constants of $\mathrm{VE}$ and $\mathrm{VCO}_{2}$ during both running and walking. When we compared the time constants of $\mathrm{VCO}_{2}$ and VE with that of $\mathrm{VO}_{2}$, a significant difference was found during both running and walking. Ventilation was found to be coupled to $\mathrm{VO}_{2}$ and in both running and walking VE was found to "track" $\mathrm{VCO}_{2}$ (see Figs. 2 and 3). One reason for the delay in the time constants of $\mathrm{VE}$ and $\mathrm{VCO}_{2}$ when compared with $\mathrm{VO}_{2}$ during the onset of work is the high solubility of $\mathrm{CO}_{2}$ in the body tissues (Fahri and Rahn, 1976). In contrast, the body's ability to store oxygen is small. There are limited stores of oxygen bound to myoglobin but the majority of the oxygen in the body is bound to haemoglobin. This increased extravascular capacitance of the body for $\mathrm{CO}_{2}$ over $\mathrm{O}_{2}$ is reflected in the transient decrease in $\mathrm{R}$ values at the start of exercise. An examination of Fig. 4 shows transient decreases in $\mathbf{R}$ values during the first minute of exercise for both running and walking.
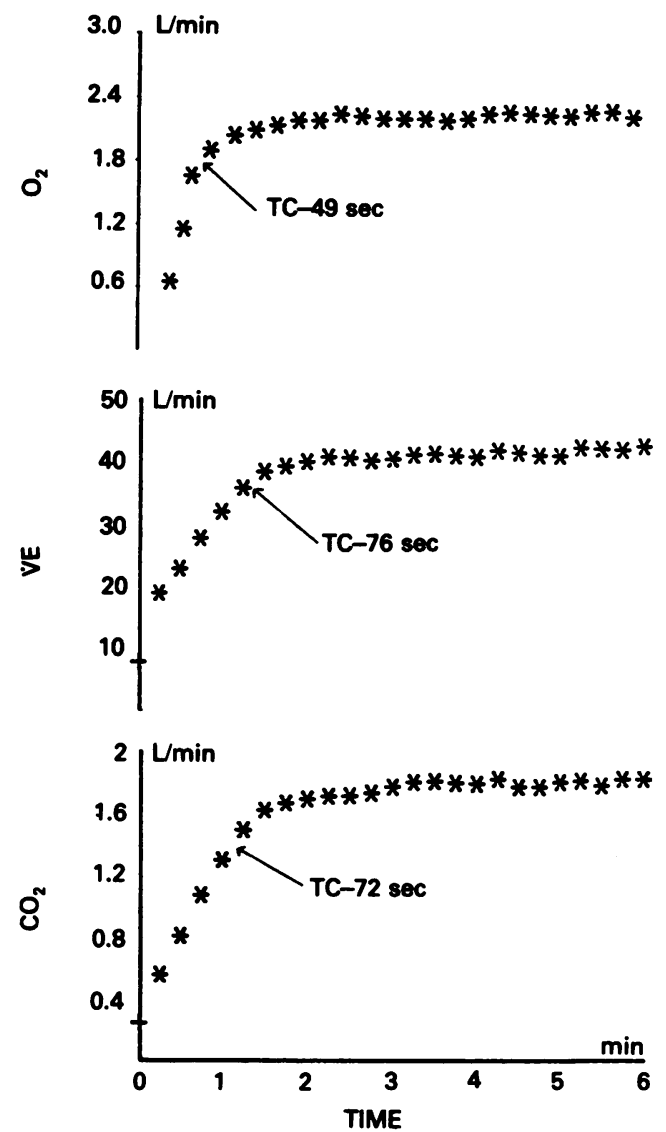

Fig. 2: A comparison of the time course curves for $\mathrm{VE}, \mathrm{VCO}_{2}$ and $\mathrm{VO}_{2}$ during walking. Time constants, TC, are given for each variable.
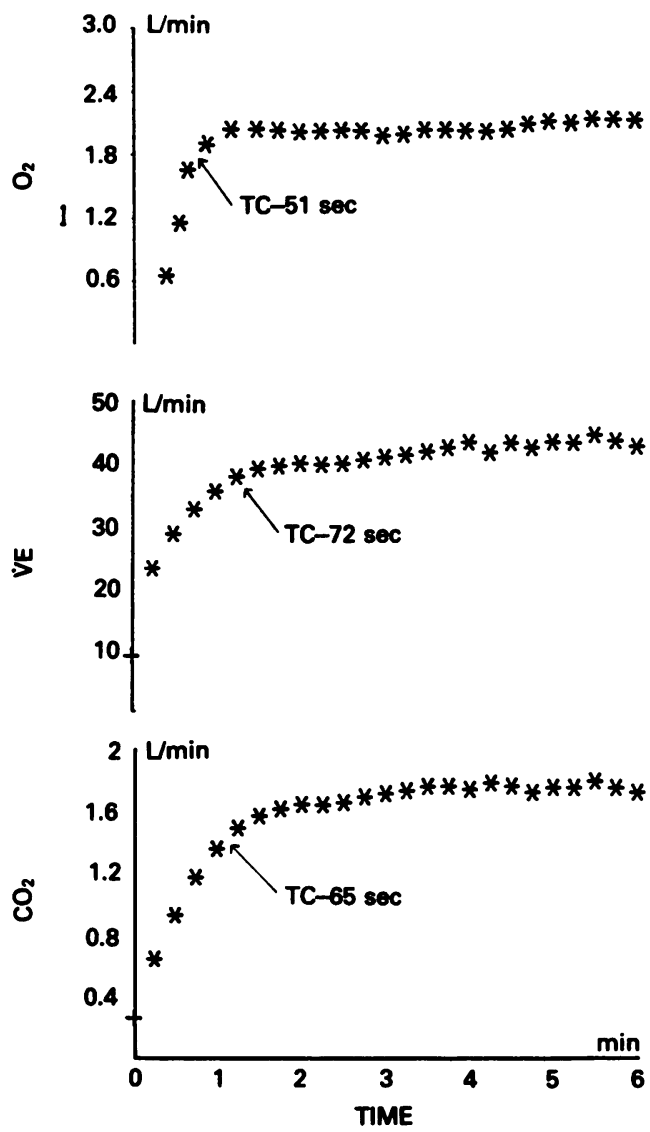

Fig. 3: A comparison of the time course curves for $\mathrm{VE}_{1} \mathrm{VCO}_{2}$ and $\mathrm{VO}_{2}$ during running. Time constants, TC, are given for each variable. 

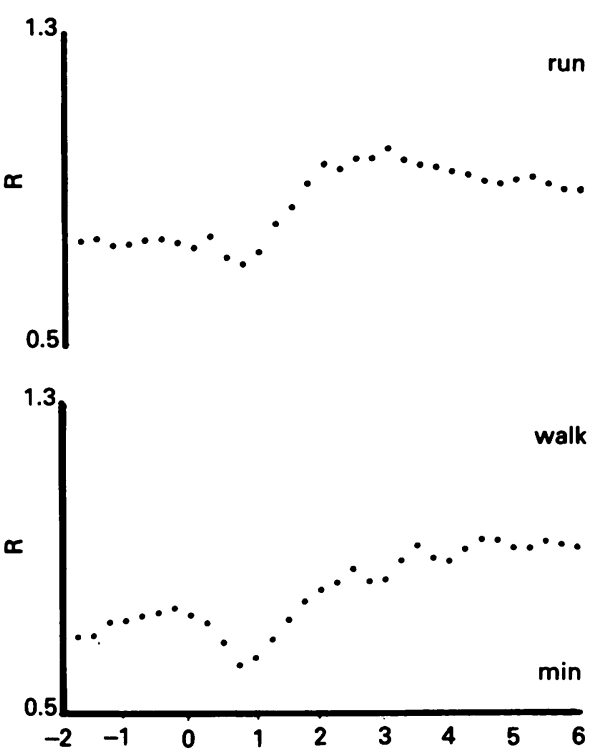

Fig. 4: The effects of exercise on $R$ values during running and walking. Zero on the $X$ axis indicates the start of exercise.

Our findings of a closely aligned $\mathrm{VE}-\mathrm{V} \mathrm{CO}_{2}$ response at the start of exercise and a faster response for $\mathrm{VO}_{2}$ are congruous with those found in investigations using square wave (Diamond et al, 1977; Linnarsson, 1974) and sinusoidal (Casaburi et al, 1977) work forcings. The coupling of $\mathrm{VE}$ and $\mathrm{VCO}_{2}$ irrespective of stride frequency during steady state exercise is indicative of the fact that VE is tightly coupled to the metabolic demands placed on the body. Further evidence for the VE-VCO, link is noted during the transition from rest to exercise when VE is found to "track" $\mathrm{VCO}_{2}$.

\section{References}

Bechbache, R. R. and Duffin, J., 1977 "The entrainment of breathing frequency by exercise rhythm". J.Physiol. 272: 553-561.

Bramble, D. M. and Carrier, D. R., 1983 "Running and breathing in mammals". Science 219: 251-256.
Caiozzo, V. J., Davis, J. A., Ellis, J. F., Azus, J. L., Vandagriff, R., Prieto, C. A. and McMaster, W. C. 1982 "A comparison of gas exchange indices used to detect the anaerobic threshold". J.Appl.Physiol. 53: 1184-1189.

Casaburi, R., Whipp, B. J., Wasserman, K., Beaver, W. L. and Koyal, S. N., 1977 "Ventilatory and gas exchange dynamics in response to sinusoidal work". J.Appl.Physiol. 42: 300-311.

Davis, J. A., Vodak, P., Wilmore, J. H., Vodak, J. and Kurtz, P., 1976 "Anaerobic threshold and maximal aerobic power for three modes of exercise". J.Appl.Physiol. 41: 544-550.

Dejours, P., 1967 "Neurogenic factors in the control of ventilation during exercise". Circulation Res.Suppl. 1 to Vol. 20 and 21: 146-153.

Diamond, L. B., Casaburi, R., Wasserman, K. and Whipp, B. J., 1977 "Kinetics of gas exchange and ventilation in transition from rest or prior exercise". J.Appl.Physiol. 43: 704-708.

Dixon, M. E., Stewart, P. B., Mills, F. C., Varvis, C. J. and Bates, J. V., 1961 "Respiratory consequences of passive body movements". J.Appl. Physiol. 16: 30-34.

Eldridge, F. L., 1977 "Maintenance of respiration by central neural feedback mechanisms". Fed.Proc. 36: 2400-2404.

Eldridge, F. L., Milhorn, D. E. and Waldrop, T. G., 1981 "Exercise hyperpnea and locomotion: parallel activation from the hypothalamus". Science 211: 844-846.

Fahri, L. E., and Rahn, H., 1976 "Dynamics of carbon dioxide stores". Anesthaesiology 21: 604-614.

Filley, G. F. and Heineken, F. G., 1976 "A gas disequilibrium theory". Br.J.Dis. Chest 70: 223-225

Hanson, P., Claremont, A., Dempsey, J. and Reddan, W., 1982 "Determinants and consequences of ventilatory responses to competitive endurance running". J.Appl.Physiol. 52: 615-623.

Jasinskas, C. L., Wilson, B. A. and Hoare, J., 1980 "Entrainmnent of breathing rate to movement frequency during work at two intensities". Respir. Physiol. 42: 199-209.

Kao, F. F., Schilig, B. and Brooks, C. McC., 1955 "Regulation of respiration during induced muscular work in decerebrate dogs". J.Appl.Physiol. 7: 379-386.

Kao, F. F., Michel, C., Mei, S. S. and Li, W. K., 1963 “Somatic afferent influence on respiration". Ann.N.Y.Acad.Sci. 109: 696-708.

Kay, J. D. S., Petersen, E. S. and Vejby-Christiansen, H., 1975 "Mean and breath-by-breath pattern of breathing in man during steady-state exercise". J.Physiol. 251: 657-669.

Linnarsson, D., 1974 "Dynamics of pulmonary gas exchange and heart rate changes at start and end of exercise". Acta Physiol.Scand.(Suppl.) 415: $1-68$.

McMurray, R. G. and Ahlborn, S. W., 1982 "Respiratory responses to running and walking at the same metabolic rate". Respir.Physiol. 47: 257-265.

Wasserman, K., Whipp, B. J. and Castagna, J., 1974 "Cardiodynamic hyperpnea: hyperpnea secondary to cardiac output increase". J.Appl.Physiol. 36: 457-464.

Yamamoto, W. S., 1962 "Transmission of information in the arterial blood stream with particular reference to carbon dioxide". Biophys.J. 2: 143-159.

Title:

\section{BOOK REVIEW}

\section{A BIBLIOGRAPHY OF RESEARCH PAPERS ON PHYSIQUE, SOMATOTYPING AND BODY COMPOSITION RELATED TO SPORTS PERFORMANCE. 2nd Edition}

Author: Peter Bale 1985

Publisher: $\quad$ Brighton Polytechnic, Chelsea School of Human Movement, Denton Road, EASTBOURNE, Sussex BN20 7SR Price: $£$ 3.50 55 pages A4 typewritten Soft cover ring binding

This second edition of "Bale's Bibliography of Body Composition" (and can we not use this as a much easier title than the one the author gives the work?) updates the comprehensive lists of references from the first edition. As before, the references are given alphabetically in each of the eighteen sections, each section being devoted to one group of sports, such as "Athletics - track, field and distance running", or "table tennis, tennis and squash". Inevitably, many of the 600 references are duplicated; for example, J. M. Tanner's 'Physique of the Olympic Athlete' is quoted in several sections, and three of J. Lindsay Carter's papers in even more. As well as the groups of specific sports, sections are devoted to nutrition and to training, both related to physique - and most of the significant and less significant papers of the past twenty years are listed.

A few unfortunate errors have been missed in proof; the small circle above the $\AA$ of $\AA$ strand's name, which makes it the penultimate, not the first letter of the Norwegian alphabet; the dot above the $\mathrm{V}$ in $\mathrm{VO}_{2}$ max, indicating the rate of oxygen uptake, and worst of all, the misspelling on several occasions of the names of the Curetons, T. K. and his son, K. J., both spelt several times as "Curton". Several references are made to the "Journal of Sports Medicine" without specifying which. From the volume numbers and years I assume this is the "Journal of Sports Medicine and Physical Fitness". Apart from this, the lists provide a useful source of reference for any student or scientist interested in physique assessment, and the author is to be congratulated on the production of a very helpful research tool, at a price a student can afford for himself. Cash with order to the College, postage and packing included. 
RESEARCH

The Institute will undertake research projects linked with other London organisations.

\section{TREATMENT}

There are no immediate plans for treatment of sports injuries but its activities should do much to improve the standard of care of sportsmen, particularly in London.

\section{LINKS}

It is hoped that close links will be forged with existing sports medicine and sports science organisations as well as sports administrative bodies and academic institutions in London.

\section{COUNCIL}

The Council of Management is chaired by Mary Glen-Haig of the British Olympic Association and has representatives from sport, academic medicine and the GLC.

\section{STAFF}

Staff recruitment is commencing shortly.

Further information is available from the Medical Director, Dr. Dan Tunstall-Pedoe London Sports Medicine Institute c/o Medical College of St. Bartholomew's Hospital Charterhouse Square London EC1M 6BO

\section{ERRATA}

1. It is regretted that the following paper was omitted from the Author Index (19:4) and entered incompletely in the Subject Index.

Ergen, E., Sardella, F. and Dal Monte, A. 1985 "The relationship of maximal alactacid anaerobic power to somatotype in trained subjects" Brit.J.Sports Med. 19, 221-223.

2. Berry, M. J., Bacharach, D. W. and Moritani, T. 1985 "Stride frequency and ventilation at constant carbon dioxide output" Brit.J.Sports Med. 210-213.

Table I was incorrect and should read as follows

TABLE I

Mean physical and some physiological characteristics of subjects.

\begin{tabular}{crrcccc}
\hline & $\begin{array}{c}\text { Age } \\
(\mathrm{yrs})\end{array}$ & $\begin{array}{c}\text { Height } \\
(\mathrm{cm})\end{array}$ & $\begin{array}{c}\text { Weight } \\
(\mathrm{kg})\end{array}$ & $\begin{array}{c}\mathrm{VO}_{\text {m }} \text { max } \\
(\mathrm{l} / \mathrm{min})\end{array}$ & $\begin{array}{c}\mathrm{AT}^{*} \\
(\mathrm{l} / \mathrm{min})\end{array}$ & $\begin{array}{c}\mathrm{AT}^{*} \\
\left(\% \mathrm{VO}_{2} \text { max }\right)\end{array}$ \\
\hline Mean & 30.8 & 163.6 & 76.9 & 3.82 & 2.44 & 63.9 \\
SD & 5.2 & 25.6 & 10.6 & 0.73 & 0.57 & 11.7 \\
\hline
\end{tabular}

